\title{
Characterization and Differentiation of Iron Status in Anemic Very Low Birth Weight Infants Using a Diagnostic Nomogram
}

\author{
David C. Kasper ${ }^{a}$ b John A. Widness ${ }^{c}$ Nadja Haiden ${ }^{a}$ Angelika Berger ${ }^{a}$ \\ Michael Hayde ${ }^{a}$ Arnold Pollak ${ }^{a}$ Kurt R. Herkner ${ }^{a, b}$ \\ ${ }^{a}$ Department of Pediatrics and Adolescent Medicine, and ${ }^{\mathrm{b}}$ Research Core Unit of Pediatric Biochemistry \\ and Analytics, Medical University of Vienna, Vienna, Austria; ' Department of Pediatrics, College of Medicine, \\ University of lowa, lowa City, lowa, USA
}

\section{Key Words}

VLBW infants $\cdot$ Diagnostic plot $\cdot$ Ferritin index $\cdot \operatorname{sTfR} \cdot \mathrm{CHr} \cdot$ Iron deficiency $\cdot$ Erythropoiesis

\begin{abstract}
Background: In the early weeks of life, very low birth weight (VLBW) infants experience intense laboratory blood sampling leading to clinically significant anemia and the need for red blood cell transfusion. Although controversial, treatment with recombinant human erythropoietin (EPO) and iron has been recommended to stimulate erythropoiesis; optimal dosing of EPO and iron is still uncertain. Objectives: To assess the validity of a four-quadrant diagnostic plot of iron availability (ferritin index) versus iron demand for erythropoiesis (reticulocyte hemoglobin content, $\mathrm{CHr}$ ) for differentiating iron status in anemic VLBW infants. Methods: Study subjects were enrolled in a previously reported randomized controlled trial of clinically stable VLBW infants $<31$ weeks' gestation and $<1,300 \mathrm{~g}$ at birth to receive 18 days of treatment with: group 1: oral iron; group 2: EPO + oral iron, and group 3: EPO + intravenous + oral iron. Results: At the end of treatment the ferritin index was significantly higher in both EPO groups compared to the control group. By day $18, \mathrm{CHr}$ of the control group declined into the quadrant of the diagnostic plot characteristic of functional iron deficiency and anemia of chronic disease. Both EPO groups ended in
\end{abstract}

the quadrants that are characteristic for latent iron deficiency and iron deficiency anemia, respectively. Conclusions: The diagnostic plot for differentiating anemia in VLBW infants may be an informative, clinically useful tool for iron status assessment under different physiologic and therapeutic erythropoietic states. Larger additional studies in difficult patient populations are needed before the clinical utility of this diagnostic procedure can be unequivocally confirmed.

Copyright $\odot 2008$ S. Karger AG, Basel

\section{Introduction}

Very low birth weight (VLBW) infants commonly receive one or more red blood cell (RBC) transfusions during their first months of life [1]. In the majority of preterm infants, anemia is a result of multiple factors which include iatrogenic blood loss, inadequate $\mathrm{RBC}$ production, shorter RBC lifespan, insufficient iron stores, and rapid growth [2-4].

Recombinant human erythropoietin (r-HuEPO) therapy has been suggested as an alternative to RBC transfusion in the treatment of neonatal anemia. Although metaanalysis of controlled clinical studies has shown some benefit in the prevention of RBC transfusions even in extremely low birth weight infants $(<1,000 \mathrm{~g})$ [5], treatment of anemia of prematurity (AOP) with $\mathrm{r}$-HuEPO remains

\section{KARGER}

Fax +41613061234 E-Mail karger@karger.ch www.karger.com
(C) 2008 S. Karger AG, Basel

1661-7800/09/0952-0164\$26.00/0

Accessible online at:

www.karger.com/neo
David C. Kasper, MSc, $\mathrm{PhD}$

Department of Pediatrics and Adolescent Medicine

Medical University of Vienna

Waehringer Guertel 18-20, AT-1090 Vienna (Austria)

Tel. +43 140400 2756, Fax +43 140400 3200, E-Mail david.kasper@meduniwien.ac.at 
Fig. 1. Diagnostic plot for identifying the different erythropoietic states with therapeutical implications for the treatment of different phases of iron deficiency adapted from Thomas et al. [11]. ${ }^{\text {a Therapeutic im- }}$ plications for the treatment of different phases of iron deficiency according to Thomas et al. [11].

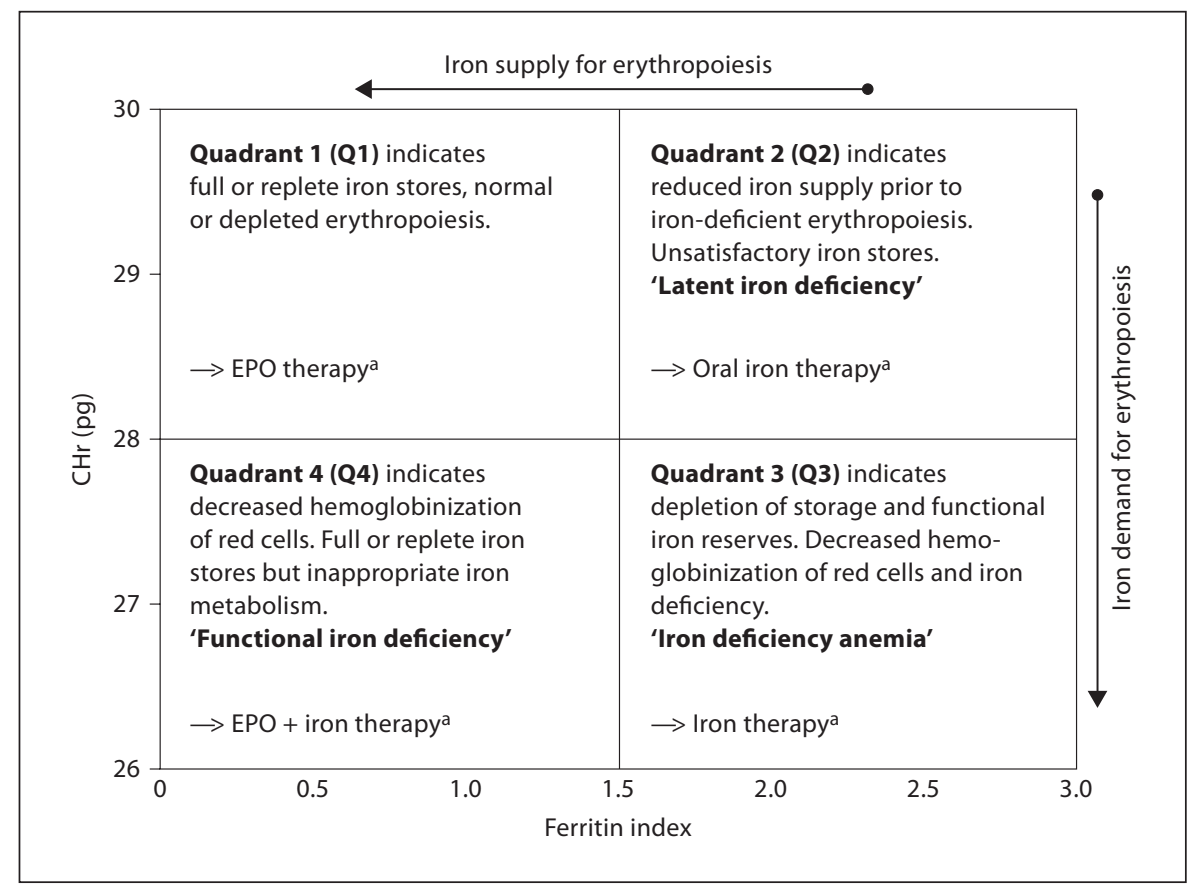

controversial [6-8]. This controversy has in part focused on conflicting strategies concerning what constitutes optimal iron supplementation during $\mathrm{r}-\mathrm{HuEPO}$ treatment of anemic infants, i.e. identification of an r-HuEPO and iron-dosing schedule that provides adequate available iron to meet the needs of accelerated erythropoiesis while avoiding the risk of iron toxicity.

Unfortunately, characterization of iron-deficient states in infants is challenging. In addition to traditional parameters such as complete blood count and biochemical markers of iron metabolism, e.g., serum transferrin, transferrin saturation and serum ferritin, more recent parameters used in defining iron status and iron-deficient states include zinc erythrocyte protoporphyrin, soluble transferrin receptor (sTfR), and the ferritin index (FI) [9]. Zinc erythrocyte protoporphyrin is non-specific since its levels increase either when erythropoiesis is stimulated or when early functional iron deficiency (FID) is present. The interpretation of both sTfR and the FI is useful in the evaluation of iron status and erythropoietic activity as shown by Dimitriou et al. [9] in children and neonates. High sTfR levels indicate increased iron demand when iron stores are being depleted. Consequently the measurement of sTfR is helpful for investigating the pathophysiology of anemia by allowing the evaluation of the adequacy of marrow proliferative capacity and the erythropoietic response to various therapies [10].
Recently, the combination of hemoglobin content of reticulocytes $(\mathrm{CHr})$, an early indicator of iron demand, and FI have been investigated by Thomas et al. [11, 12] as promising diagnostic tools for classifying and monitoring of iron deficiency in the anemia of chronic disease (ACD) in adult cancer patients. Thomas et al. [11] speculated that the diagnostic plot might also be a useful tool in assessing iron status in a broad spectrum of other anemias, including classical iron deficiency, end-stage renal failure and anemia of infection and inflammation. These investigators have devised a promising method for describing the relationship of FID (represented by $\mathrm{CHr}$ ) to the availability of iron for erythropoiesis (represented by FI). These authors used a plot of these two variables to describe this relationship. Doing so offers the advantage of classifying iron deficiency into four discrete states (fig. 1): quadrant 1 (Q1) indicates full or replete iron stores, quadrant 2 (Q2) indicates unsatisfactory iron stores prior to iron-deficient erythropoiesis - latent iron deficiency, quadrant $3(\mathrm{Q} 3)$ indicates depletion of iron storages and decreased hemoglobinization of red cells iron deficiency anemia, and quadrant 4 (Q4) indicates full or replete iron stores but inappropriate iron metabolism - FID. This plot offers the potential for monitoring erythropoietic activity, FID and the adequacy of iron availability for EPO-stimulated RBC production. 
Table 1. Clinical data at birth, start of treatment and during treatment

\begin{tabular}{|c|c|c|c|c|}
\hline Study group & Oral iron & $\mathrm{EPO}+$ oral iron & $\mathrm{EPO}+\mathrm{IV}$ iron & $\mathrm{p}$ value \\
\hline \multicolumn{5}{|l|}{ At birth } \\
\hline Weight & $1,021 \pm 84^{*}$ & $923 \pm 74$ & $1,093 \pm 66$ & 0.28 \\
\hline \multicolumn{5}{|l|}{ At start of treatment } \\
\hline Age, days & $27.2 \pm 4.5$ & $25.1 \pm 3.3$ & $23.3 \pm 2.9$ & 0.75 \\
\hline Weight & $1,281 \pm 74$ & $1,095 \pm 83$ & $1,266 \pm 81$ & 0.20 \\
\hline Phlebotomy loss, ml/kg & $16.5 \pm 5.4$ & $16.3 \pm 3.8$ & $10.6 \pm 2.0$ & 0.49 \\
\hline \multicolumn{5}{|l|}{ During treatment } \\
\hline Caloric intake, $\mathrm{kcal} / \mathrm{kg} / \mathrm{day}$ & $111 \pm 3.9$ & $109 \pm 4.4$ & $106 \pm 3.6$ & 0.69 \\
\hline Weight gain, $\mathrm{g} / \mathrm{kg} /$ day & $15.8 \pm 1.4$ & $15.1 \pm 0.9$ & $14.0 \pm 0.7$ & 0.47 \\
\hline Weight at study exit, g & $1,700 \pm 87$ & $1,441 \pm 111$ & $1,636 \pm 102$ & 0.19 \\
\hline Phlebotomy loss, $\mathrm{ml} / \mathrm{kg}$ & $5.9 \pm 0.3$ & $8.8 \pm 1.2$ & $6.3 \pm 0.7$ & 0.05 \\
\hline
\end{tabular}

* Mean \pm SEM. All between-group comparisons demonstrated no statistically significant differences.

The aim of the study was to apply the diagnostic plot to the results of a previous study of r-HuEPO and irontreated VLBW infants to assess whether this diagnostic tool is suitable for differentiating iron-deficient stages in AOP [3]. We hypothesized that the information derived has potential for being useful in therapeutic decisionmaking regarding the need for iron replacement and/or $\mathrm{r}-\mathrm{HuEPO}$ therapy in anemic infants.

\section{Methods}

Participants and Study Design

Using the diagnostic plot to assess iron status relative to $r$ $\mathrm{HuEPO}$ and iron therapy, we retrospectively analyzed previously described data from a randomized controlled trial from clinically stable VLBW infants $<31$ weeks of gestation and $<1,300 \mathrm{~g}$ birth weight [3].

In brief, inclusion criteria postnatal age $>1$ week, hematocrit $>30 \%$, phlebotomy loss averaging $<1.0 \mathrm{ml} /$ day over the previous 3 days, enteral caloric intake $>20 \mathrm{kcal} / \mathrm{kg} /$ day and stable respiratory status defined as mean oxygen saturation $>90 \%$ in a fraction of inspired oxygen $\leq 0.40$ for $>48 \mathrm{~h}$ regardless of ventilation. Infants excluded were those who received RBC transfusions 3 days before study entry or during the study, those with an active, culture-proven infection, a major malformation, electroencephalographic-proven seizures, hypertension, intraventricular hemorrhage $\geq$ grade III, immune hemolytic disease, necrotizing enterocolitis, or surgery. Among the study participants who began the study, 3 infants with sepsis or sepsis-like episodes, 2 with necrotizing enterocolitis, 2 who received RBC transfusions were excluded.

There were no statistical differences among the three study groups for common neonatal morbidities including respiratory distress syndrome $(\mathrm{p}=0.65)$, bronchopulmonary dysplasia (oxygen dependency at 36 weeks of postconceptional age; $\mathrm{p}=0.31$ ),
Table 2. Study treatment groups

\begin{tabular}{llll}
\hline Treatment modality & $\begin{array}{l}\text { Group 1 } \\
\text { oral iron }\end{array}$ & $\begin{array}{l}\text { Group 2 } \\
\text { EPO + } \\
\text { oral iron }\end{array}$ & $\begin{array}{l}\text { Group 3 } \\
\text { EPO + oral + } \\
\text { IV iron }\end{array}$ \\
\hline Oral iron, mg/kg/day & 9 & 9 & 9 \\
IV iron, mg/kg/day & - & - & 2 \\
EPO, U/kg/day & - & 300 & 300 \\
\hline
\end{tabular}

patent ductus arteriosus $(\mathrm{p}=0.60)$ and retinopathy of prematurity $(\mathrm{p}=0.32)$. There were also no significant differences identified among the three study groups for birth weight or in age, body weight, or phlebotomy loss at the prior to and during the treatment period (table 1).

The 21-day study consisted of a 3-day run-in baseline period during which all subjects received $9 \mathrm{mg} / \mathrm{kg} /$ day of iron polymaltose complex (IPC; Ferrum Hausmann Syrup, Vifor International, St. Gallen, Switzerland). To remain in the study, subjects were not allowed to receive treatment with RBC transfusion. Study participants were randomized to receive 18 days of oral iron alone (group 1: oral iron; control group), r-HuEPO + oral iron (group 2: $\mathrm{EPO}+$ oral iron), or r-HuEPO + intravenous (IV) iron (group 3: $\mathrm{EPO}+\mathrm{IV}$ iron) treatment beginning after a 3-day run-in period (table 2).

\section{Analytical Procedures}

Hematological parameters and the iron status (sTfR, ferritin) were determined on peripheral venous or arterial blood drawn on treatment days $-3,0,4,11$, and 18 . Hematological parameters were analyzed immediately. Serum and plasma were aliquoted and stored at $-80^{\circ} \mathrm{C}$ for later analysis. Blood counts, reticulocyte counts, $\mathrm{RBC}$ and $\mathrm{CHr}$ indices were performed on fresh whole blood samples by flow cytometry (Technicon H.3 Autoanalyzer, 
Table 3. Comparison of laboratory data at the start (day 0) and the end of treatment (day 18).

\begin{tabular}{|c|c|c|c|c|c|}
\hline & Day & $\begin{array}{l}\text { Oral iron } \\
(\mathrm{n}=9)\end{array}$ & $\begin{array}{l}\mathrm{EPO}+\text { oral iron } \\
(\mathrm{n}=10)\end{array}$ & $\begin{array}{l}\text { EPO + IV iron } \\
(\mathrm{n}=10)\end{array}$ & $\begin{array}{l}\text { ANOVA } \\
\text { p value }\end{array}$ \\
\hline \multirow[t]{2}{*}{ sTfR, mg/l } & 0 & $2.32 \pm 0.41$ & $2.19 \pm 0.35$ & $1.76 \pm 0.13$ & NS \\
\hline & 18 & $2.59 \pm 0.57$ & $5.57 \pm 0.53$ & $6.69 \pm 0.71$ & $<0.01^{\mathrm{a}}$ \\
\hline \multirow[t]{2}{*}{ Ferritin, $\mu \mathrm{g} / \mathrm{l}$} & 0 & $309.8 \pm 32.1$ & $380.9 \pm 72.3$ & $352.4 \pm 55.4$ & NS \\
\hline & 18 & $171.2 \pm 35.6$ & $233.1 \pm 43.0$ & $852.1 \pm 167.5$ & $<0.01^{\mathrm{b}, \mathrm{c}}$ \\
\hline \multirow{2}{*}{ Ferritin index } & 0 & $0.95 \pm 0.17$ & $0.89 \pm 0.16$ & $0.71 \pm 0.06$ & NS \\
\hline & 18 & $1.21 \pm 0.27$ & $2.50 \pm 0.32$ & $2.34 \pm 0.24$ & $<0.05^{\mathrm{a}}$ \\
\hline \multirow[t]{2}{*}{$\mathrm{CHr}, \mathrm{pg}$} & 0 & $27.6 \pm 0.5$ & $28.0 \pm 0.6$ & $28.6 \pm 0.8$ & NS \\
\hline & 18 & $26.6 \pm 0.3$ & $28.8 \pm 0.6$ & $27.5 \pm 0.4$ & $<0.05^{\mathrm{d}}$ \\
\hline \multirow[t]{2}{*}{$\mathrm{Hb}, \mathrm{g} / \mathrm{l}$} & 0 & $112 \pm 3$ & $117 \pm 8$ & $115 \pm 5$ & NS \\
\hline & 18 & $92 \pm 3$ & $102 \pm 7$ & $113 \pm 6$ & $<0.05^{\mathrm{a}}$ \\
\hline \multicolumn{6}{|c|}{$\begin{array}{l}\text { Values shown are mean } \pm \text { SEM. NS }=\text { Not significant. } \\
\text { a EPO + IV iron group and EPO + oral iron group compared with the oral iron group. } \\
{ }^{b} \text { EPO + IV iron group compared with the oral iron group. } \\
{ }^{c} \text { EPO + IV iron group compared with EPO + oral iron group. } \\
{ }^{d} \text { EPO + oral iron group compared with the oral iron group. }\end{array}$} \\
\hline
\end{tabular}

Bayer Austria GmbH, Vienna, Austria). Ferritin was determined by a radioimmunoassay (Bio-Rad Quantimmune Ferritin IRMA, Bio-Rad Diagnostics Group, Hercules, Calif., USA). Transferrin was measured by an antigen-antibody turbidimetric method using rabbit human transferrin antiserum (Boehringer Mannheim, Indianapolis, Ind., USA). sTfR concentration was determined by an ELISA (Ramco Laboratories, Inc., Houston, Tex., USA). The FI was calculated using the following equation: sTfR [mg/l]/log ferritin $[\mu \mathrm{g} / \mathrm{l}][9]$.

\section{Statistical Analyses}

Within-group comparisons were performed by paired-samples t test (two-tailed). Between-group comparisons were performed by independent-samples t test and ANOVA with Bonferroni posthoc multiple comparisons test for normal distributed data or Mann-Whitney U test for non-parametric sample distribution. Results are expressed as mean \pm SEM. $p<0.05$ was considered statistically significant. Calculations were done with SPSS 14.0 (SPSS, Inc., Chicago, Ill., USA).

\section{Results}

The age of subjects at study entry was $23 \pm 2.9$ days. Demographic and clinical features of the three study groups including gestational age and birth weight have been described previously and did not differ among the three groups at treatment day -3 or baseline. On day 0 , none of the hematological or serological parameters demonstrated significance between group differences (table 3) [3].

Diagnostic Nomogram for Anemic VLBW Infants
As anticipated, subsequent hematological and serological parameters demonstrated significant differences among the groups according to their therapeutic assignment (fig. 2a-c). Posttreatment changes in sTfR concentration were significantly higher in group $2(\mathrm{EPO}+$ oral iron) and group 3 (EPO + IV iron) compared to group 1 (oral iron; control group) ( $\mathrm{p}<0.01$; fig. 2a). The sTfR values increased significantly from baseline in both EPO groups on days 11 and 18 compared to the control group. Similarly, there was a posttreatment increase in the FI for both EPO groups starting at day $11(\mathrm{p}<0.05)$ compared to the control group (fig. 2b). A significant increase in $\mathrm{CHr}$ occurred at day $18(\mathrm{p}<0.05)$ in group 2 , while in group 3 only a trend toward higher $\mathrm{CHr}$ values was observed which did not quite achieve statistical significance ( $\mathrm{p}=0.059)$ (fig. 2c).

Beginning on treatment day -3 and continuing to day 18 at the end of treatment, serial iron status laboratory data for each group were plotted (CHr vs. FI; fig. 3) according to the method of Thomas et al. [11]. As the study period progressed, the pattern of laboratory findings of group 1 infants differed significantly in the course of $\mathrm{CHr}$ and FI in comparison to both r-HuEPO-treated groups. For group 1 infants, $\mathrm{CHr}$ by the end of study declined into Q4, the quadrant is indicative of functional iron-deficient anemia, e.g., for ACD. In contrast, the two r-HuEPO-treated groups moved to the right, i.e. an increase in FI was observed. Although the courses of group 2 and group 3 paralleled one another over time beginning

Neonatology 2009;95:164-171 

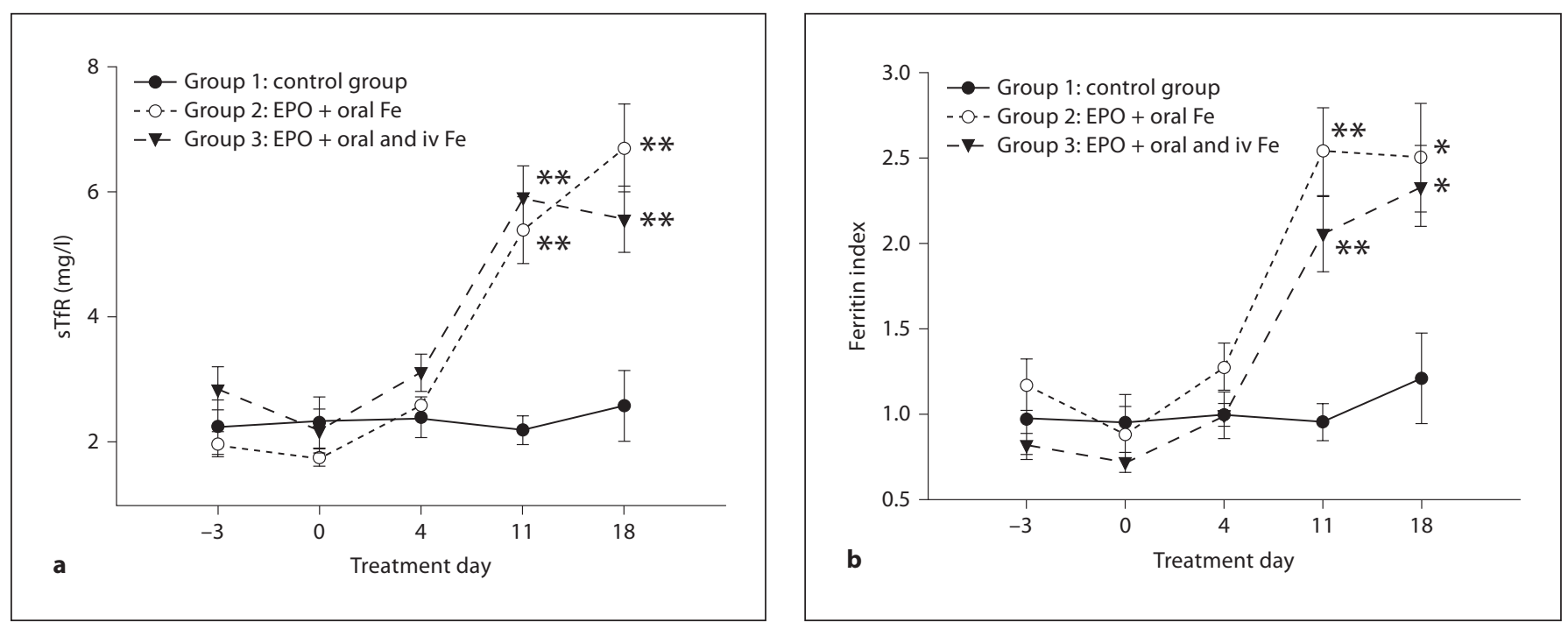

Fig. 2. Change in sTfR (a), ferritin index (b) and $\mathrm{CHr}$ (c) during the treatment by study group. Data are shown as mean \pm SEM. Post hoc statistical significance compared with group 1 is indicated by the asterisk(s): ${ }^{*} \mathrm{p}<0.05 ;{ }^{* *} \mathrm{p}<0.01$; ns $=$ not significant.

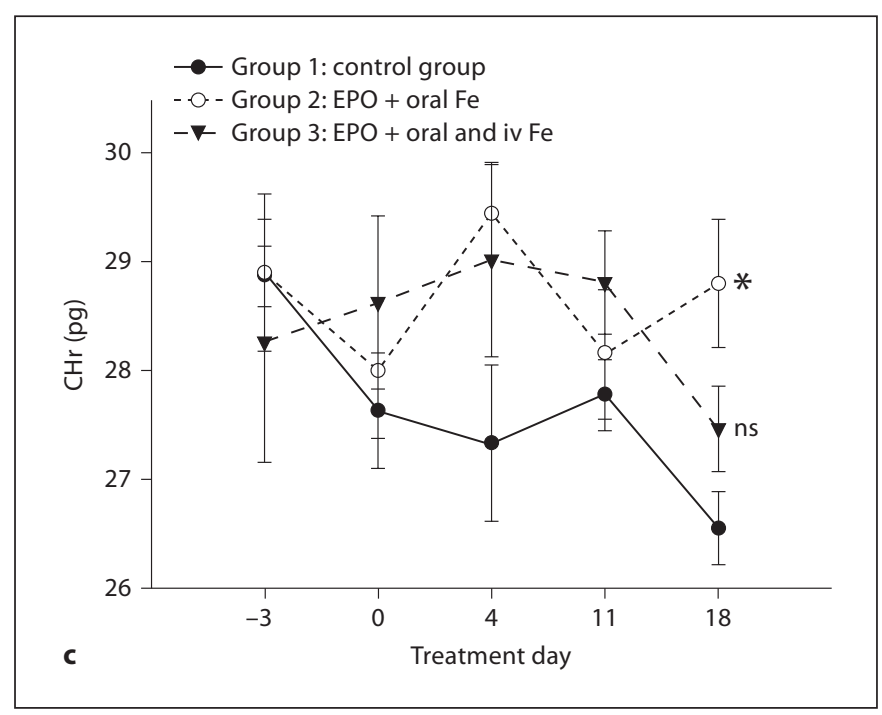

with the initiation of r-HuEPO treatment, on day 18, group 2 infants (EPO and oral iron) ended up in Q2 (latent iron deficiency) while group 3 IV EPO + IV irontreated infants ended in Q3 (iron-deficient anemia).

\section{Discussion}

The aim of the present study was to examine the clinical utility of using a diagnostic plot of Thomas et al. [11] to assess iron availability for erythropoiesis in VLBW infants with AOP as an informative tool for clinicians. The data analyzed were derived from a previous study of VLBW premature infants treated with two different $r$ -

$\mathrm{HuEPO}$ and iron-dosing regimens used in the treatment of AOP. This diagnostic plot utilizes two sensitive and specific parameters of the adequacy of iron for erythropoiesis for the $\mathrm{x}$ - and $\mathrm{y}$-axes: FI and $\mathrm{CHr}$. The $\mathrm{CHr}$ and the FI were used as the key hematological indicators for the intensity of the demand for iron and the adequacy of iron supply, respectively. The plot was used to identify the initial and subsequent erythropoietic and iron status of the three study groups that differed in the r-HuEPO and oral and parenteral iron supplementation each received. $\mathrm{CHr}$ has been used in the diagnosis of different iron-deficient states and in the response to iron and/or r-HuEPO treatment [11, 13-17]. Importantly, CHr provides a direct assessment of the incorporation of iron 
Fig. 3. Diagnostic plot for identifying the different erythropoietic states. The course of each group is plotted from the 3-day run-in baseline period (day $=-3$ ) through the start of treatment $($ day $=0)$ continuing on to the end of treatment (day $=18)$. The $\mathrm{x}$-axis represents the biochemical indicators for iron supply (sTfR/log ferritin, i.e., ferritin index) and the $\mathrm{y}$-axis represents the hematological indicator for iron demand by erythropoiesis (CHr). Q1-4 indicates quadrants 1 to 4 .

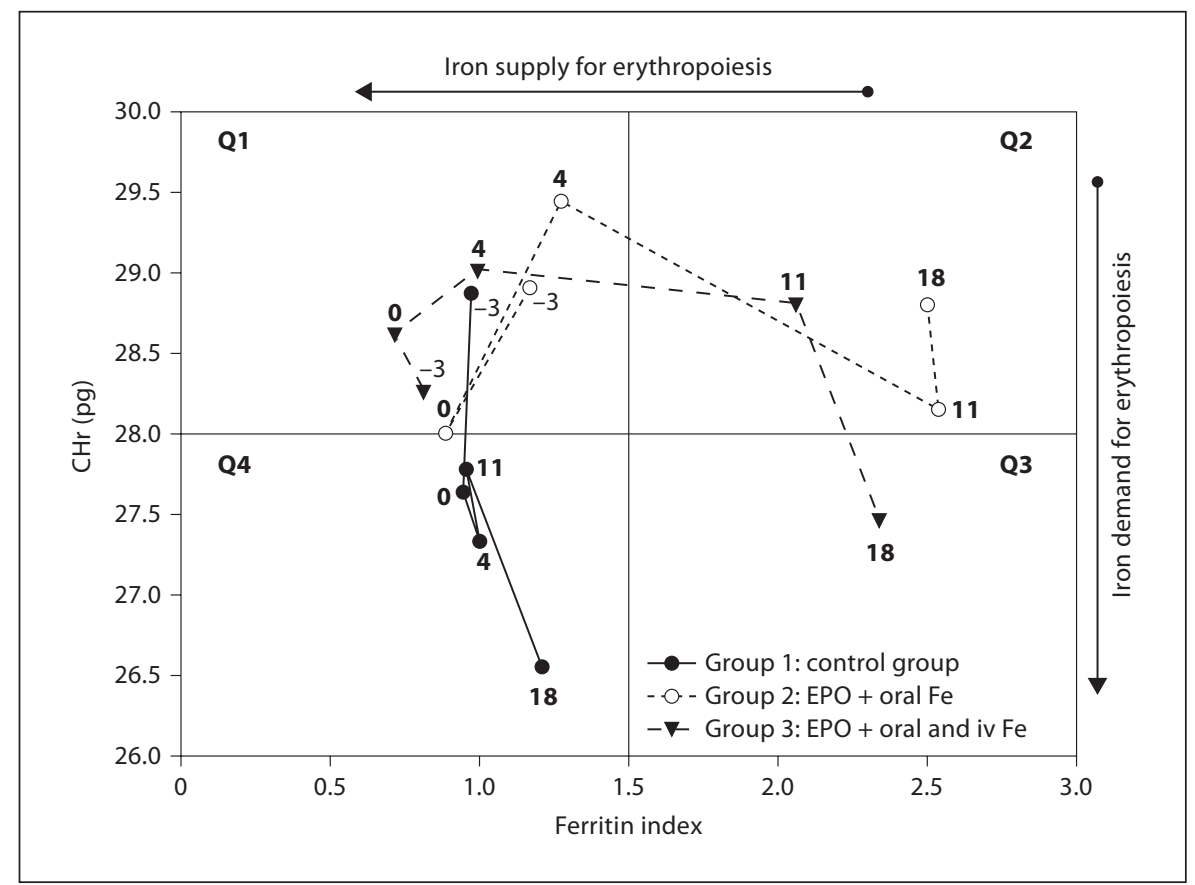

into erythrocyte hemoglobin and thus serves as a direct indicator of the recent functional availability of iron for the erythron $[13,18]$. sTfR and zinc erythrocyte protoporphyrin were proposed as useful indicators for iron deficiency [19], because both parameters are directly associated with erythropoietic activity $[10,20,21]$. Both have therefore been used to help identifying iron deficiency states in children $[9,22,23]$. The acute-phase reactant, ferritin, has primarily been used as an indicator of iron storage [24-26]. In the absence of inflammatory disease, the sTfR to ferritin ratio (FI) is inversely correlated with iron stores in various anemic states, including the ACD and FID [11].

In the previous study from which the present data were derived, we investigated the efficacy and safety of high doses of EPO/iron therapy on the AOP [3]. In our application of the diagnostic plot of Thomas et al. [11] to the present data beginning on day -3 , all three groups started in the upper left quadrant (Q1) of the plot (fig. 3), i.e. indicating that baseline iron status of all three groups were adequate relative to their erythropoietic demand. We speculate that the control group became increasingly anemic as a result of multiple factors impacting iron status including: (1) low endogenous EPO production, (2) diminished iron stores as a result of rapid growth, and (3) on going phlebotomy loss. We further speculated that the later two of these contributed to the decrease of $\mathrm{CHr}$ ob- served in the control group despite receiving oral iron supplementation.

Without administration of EPO, the course of the control group fell into the lower left quadrant (Q4) of the diagnostic plot and remained there until the end of the treatment period on day 18 . Q4 is characteristic of anemic conditions associated with FID/ACD. These results suggest that the group 1 control subjects receiving oral iron supplementation alone experienced both $\mathrm{r}$-HuEPO and iron deficiency by the end of the study. This unanticipated finding that control group infants moved from their initial position in iron sufficient Q1 to their final position at the end of the study in Q4, characteristic of anemic conditions associated with FID/ACD, is consistent with the findings of Thomas et al. [11]. On this point, we speculate that because the control group did not receive $\mathrm{r}-\mathrm{HuEPO}$ treatment, iron was not incorporated in adequate amounts by reticulocytes. As a result, mean $\mathrm{CHr}$ values for control subjects fell below the 28 pg cutoff value for Q4. Thus, although iron stores were replete based on ferritin at treatment day $18>200 \mu \mathrm{l} / \mathrm{l}$ and a FI $<1.5$, complete hemoglobinization did not occur. As such, treatment with $\mathrm{r}-\mathrm{Hu}-$ EPO and additional iron supplementation might be considered as possible therapeutic considerations.

In contrast to the control group, both r-HuEPO-treated groups had moved into quadrant Q2 by treatment day 11. This can be interpreted as a successful response to the 
r-HuEPO therapy with a pronounced stimulation of erythropoiesis by the second week of treatment. No significant increase in $\mathrm{CHr}$ was observed in the $\mathrm{EPO}+\mathrm{IV}$ iron group $(\mathrm{p}=0.059)$ by day 18 , while in the $\mathrm{EPO}+$ oral iron group a slight, but significant, increase in $\mathrm{CHr}$ was observed compared to the control group $(\mathrm{p}<0.05)$. Based on our diagnostic plot data and the recent review of iron supplementation in preterm infants by of Ridley et al. [27], it can be hypothesized that oral iron supplementation together with EPO therapy is adequate clinical therapy for preterm infants during their period of AOP which is in accordance with the considerations of Ridley et al. [27]. By day 18, the course of group 2 ended in Q2, reflecting a latent iron deficiency. In contrast, the course of group 3 ended in Q3, indicative of classic iron deficiency anemia. Additional trials are needed to assess whether $\mathrm{r}$ HuEPO administration might be stopped at this point and if iron therapy (oral and/or IV iron) alone is sufficient as a therapeutic intervention for patients entering Q2 or Q4 of the diagnostic plot.

The diagnostic plot has served as a clinically useful tool in evaluating iron status of patients with renal anemia in which $\mathrm{CHr}$ provides helpful information regarding FID in dialysis patients receiving erythropoiesis-stimulating agents [28]. The diagnostic plot also appears helpful in monitoring iron therapy in cancer-related anemia [11]. Treatment of preterm infants with EPO and iron is one therapeutic approach for AOP exacerbated by phlebotomy (and therefore iron) loss. The diagnostic plot might also be helpful as a supporting diagnostic tool for clinicians seeking to identify the optimal r-HuEPO and iron-dosing regimens. The influence of supplementation with vitamin $\mathrm{B}_{12}$ and folic acid with or without $\mathrm{r}-\mathrm{HuEPO}$ treatment and with IV iron to reduce the need for RBC transfusion [29] is another example of a clinical situation that would be of interest to apply the diagnostic plot to determine if a positive effect in the stimulation of erythropoiesis is observed. A clinical study by Worthington-White et al. [30] indicated that premature infants require additionally vitamin
$\mathrm{B}_{12}$ and folate, and it could be shown that the severity of anemia was reduced. In their study, infants treated with vitamin $B_{12}$ alone or combined with folate had higher hemoglobin values than the untreated $(p<0.0005)$ or solely folate-treated $(\mathrm{p}<0.01)$ groups. In future studies, it will be important to include untreated infants starting at birth when both ferritin and sTfR levels are normally (i.e., in the absence of $\mathrm{r}-\mathrm{HuEPO}$ and IV iron treatment and before receiving $\mathrm{RBC}$ transfusions) at their highest.

\section{Conclusion}

Our results indicate that the diagnostic plot developed by Thomas et al. [11] offers promise as a useful tool for assessing iron status in anemic preterm infants. In its reliance on laboratory determinations performed in most hospital laboratories, the diagnostic plot has the potential for providing a readily available, real-time indicator of iron status. This has particular relevance for anemic, rapidly growing low birth weight infants during treatment with erythropoiesis-stimulating factors which result in different degrees of iron demand for hemoglobin synthesis. Additional studies carried out in a robust spectrum of clinical circumstances and other neonatal patient groups are needed before the clinical utility of this new diagnostic procedure can be unequivocally relied on.

\section{Acknowledgements}

This study was supported in part by March of Dimes (Grant FY 95-0220), by Vifor International, St. Gallen, Switzerland, JanssenCilag Pharma (Vienna, Austria), and the Verein 'Unser Kind'. The authors acknowledge the careful data and sample collection of Maria Babich, RN, the expert technical support of Robert L. Schmidt and Ron Rogers. The study was facilitated by the enthusiastic support of the nursing and physician staff of the Department of Pediatrics, University of Vienna. Most importantly, we thank the families who entrusted us with the care of their infants.

\section{References}

$\checkmark 1$ Bell EF, Strauss RG, Widness JA, Mahoney LT, Mock DM, Seward VJ, Cress GA, Johnson KJ, Kromer IJ, Zimmerman MB: Randomized trial of liberal versus restrictive guidelines for red blood cell transfusion in preterm infants. Pediatrics 2005; 115 : 1685 1691.

2 Bohler T, Leo A, Stadler A, Linderkamp O: Mechanical fragility of erythrocyte membrane in neonates and adults. Pediatr Res 1992;32:92-96.

\footnotetext{
Pollak A, Hayde M, Hayn M, Herkner K, Lombard KA, Lubec G, Weninger M, Widness JA: Effect of intravenous iron supplementation on erythropoiesis in erythropoietin-treated premature infants. Pediatrics 2001;107:78-85.

4 Widness JA: Pathophysiology, diagnosis, and prevention of neonatal anemia. Neoreviews 2000;1:e61-e68.
} 
5 Maier RF, Obladen M, Muller-Hansen I, Kattner E, Merz U, Arlettaz R, Groneck P, Hammer H, Kossel H, Verellen G, Stock GJ, Lacaze-Masmonteil T, Claris O, Wagner M, Matis J, Gilberg F: Early treatment with erythropoietin $\beta$ ameliorates anemia and reduces transfusion requirements in infants with birth weights below 1,000 g. J Pediatr 2002;141:8-15.

6 Carbonell-Estrany X, Figueras-Aloy J, Alvarez E: Erythropoietin and prematurity where do we stand? J Perinat Med 2005;33: 277-286.

7 Aher S, Ohlsson A: Late erythropoietin for preventing red blood cell transfusion in preterm and/or low birth weight infants. Cochrane Database Syst Rev 2006;3: CD004868.

8 Aher SM, Ohlsson A: Early versus late erythropoietin for preventing red blood cell transfusion in preterm and/or low birth weight infants. Cochrane Database Syst Rev 2006;3: CD004865.

9 Dimitriou H, Stiakaki E, Markaki EA, Bolonaki I, Giannakopoulou C, Kalmanti M: Soluble transferrin receptor levels and soluble transferrin receptor/log ferritin index in the evaluation of erythropoietic status in childhood infections and malignancy. Acta Paediatr 2000;89:1169-1173.

10 Beguin Y: Soluble transferrin receptor for the evaluation of erythropoiesis and iron status. Clin Chim Acta 2003;329:9-22.

-11 Thomas C, Kirschbaum A, Boehm D, Thomas L: The diagnostic plot: a concept for identifying different states of iron deficiency and monitoring the response to epoetin therapy. Med Oncol 2006;23:23-36.
2 Thomas C, Thomas L: Anemia of chronic disease: pathophysiology and laboratory diagnosis. Lab Hematol 2005;11:14-23.

13 Brugnara C, Schiller B, Moran J: Reticulocyte hemoglobin equivalent (Ret $\mathrm{He}$ ) and assessment of iron-deficient states. Clin Lab Haematol 2006;28:303-308.

14 Ullrich C, Wu A, Armsby C, Rieber S, Wingerter S, Brugnara C, Shapiro D, Bernstein $\mathrm{H}$ : Screening healthy infants for iron deficiency using reticulocyte hemoglobin content. JAMA 2005;294:924-930.

15 Thomas C, Thomas L: Biochemical markers and hematologic indices in the diagnosis of functional iron deficiency. Clin Chem 2002; 48:1066-1076

16 Brugnara C: Reticulocyte cellular indices: a new approach in the diagnosis of anemias and monitoring of erythropoietic function. Crit Rev Clin Lab Sci 2000;37:93-130.

17 Brugnara C: Iron deficiency and erythropoiesis: new diagnostic approaches. Clin Chem 2003;49:1573-1578.

18 Brugnara C: Erythrocyte membrane transport physiology. Curr Opin Hematol 1997;4: 122-127.

19 Choi JW: Sensitivity, specificity, and predictive value of serum soluble transferrin receptor at different stages of iron deficiency. Ann Clin Lab Sci 2005;35:435-439.

20 Mast AE, Blinder MA, Gronowski AM, Chumley C, Scott MG: Clinical utility of the soluble transferrin receptor and comparison with serum ferritin in several populations. Clin Chem 1998;44:45-51.

-21 Labbe RF, Vreman HJ, Stevenson DK: Zinc protoporphyrin: a metabolite with a mission. Clin Chem 1999;45:2060-2072.

-22 Lin XM, Ji CY, Liu WJ, Long Z, Shen XY: Levels of serum transferrin receptor and its response to $\mathrm{Fe}$-supplement in $\mathrm{Fe}$-deficient children. Br J Nutr 2006;96:1134-1139.
23 Vazquez Lopez MA, Carracedo A, Lendinez F, Munoz FJ, Lopez J, Munoz A: The usefulness of serum transferrin receptor for discriminating iron deficiency without anemia in children. Haematologica 2006;91:264265.

-24 Rettmer RL, Carlson TH, Origenes ML, Jack RM, Labb RF: Zinc protoporphyrin/heme ratio for diagnosis of preanemic iron deficiency. Pediatrics 1999; 104:e37.

$\checkmark 25$ Ali MA, Luxton AW, Walker WH: Serum ferritin concentration and bone marrow iron stores: a prospective study. Can Med Assoc J 1978;118:945-946.

26 Lipschitz DA, Cook JD, Finch CA: A clinical evaluation of serum ferritin as an index of iron stores. N Engl J Med 1974;290:12131216.

27 Ridley FC, Harris J, Gottstein R, Emmerson AJ: Is supplementary iron useful when preterm infants are treated with erythropoietin? Arch Dis Child 2006;91:1036-1038.

$>28$ Horl WH: Iron therapy for renal anemia: how much needed, how much harmful? Pediatr Nephrol 2007;22:480-489.

29 Haiden N, Schwindt J, Cardona F, Berger A, Klebermass K, Wald M, Kohlhauser-Vollmuth C, Jilma B, Pollak A: Effects of a combined therapy of erythropoietin, iron, folate, and vitamin $\mathrm{B}_{12}$ on the transfusion requirements of extremely low birth weight infants. Pediatrics 2006;118:2004-2013.

30 Worthington-White DA, Behnke M, Gross S: Premature infants require additional folate and vitamin $B_{12}$ to reduce the severity of the anemia of prematurity. Am J Clin Nutr 1994; 60:930-935. 